\title{
Effect of Gibberellic acid (GA) and stratification treatment on embryo ultrastructure of Taxus chinensis var. mairei seed
}

\author{
ZHANG YanJie ${ }^{1}$, LU ShunBao ${ }^{1}$ and GAO HanDong ${ }^{2 *}$ \\ ${ }^{1}$ College of Life Science, Key Lab of Protection and Utilization of Subtropic Plant Resources, Jiangxi Normal University, \\ Nanchang 330022, P. R. China. \\ ${ }^{2}$ College of Forest Resources and Environment Nanjing Forestry University, Naniing 210037, P. R. China.
}

Accepted 14 May, 2013

\begin{abstract}
Seeds of Taxus chinensis var. mairei are known for their deep dormancy that can be broken by a procedure involving variable temperature stratification. Changes of ultrastructure in seed embryo of $T$. mairei during stratification were investigated with a scan electricity microscope and a transmission electricity microscope. After 4 months of warm stratification, the following cytological changes were observed: an enlargement of the embryo and cotyledon. Two months of warm stratification following the cold treatment induced embryonic cells and apical meristems continued to divide. An abundance of electro-dense matter and a small amount of starch grain and mitochondria appeared, and the lipids in the embryonic cell gradually degraded. After four months of cold stratification treatment, one or two distinct nucleoli in the shoot apical meristem cells were observed, embryo increased in volume, the cotyledon became stretched, the lipids in the embryonic cell disappeared, the number of mitochondria increased, and the Golgi bodies appeared. We concluded that warm stratification with alternating temperatures increased the growth of embryos by cell expansion and enlargement. Cold stratification may induce a response to gibberellic acid and initiated cell division resulting in the release of physiological dormancy and subsequent germination of $T$. mairei seeds.
\end{abstract}

Key words: Taxus chinensis var. mairei, seed, scan electricity microscope (SEM), transmission electricity microscope (TEM).

\section{INTRODUCTION}

Taxus mairei is a rare taxaceae taxus specie, the majority of which is distributed in China in the Yangtze River basin, Henan Nanling Mountains, and mountains or valleys in Shaanxi, Gansu, and Taiwan. It is highly regarded for the anti-cancer active ingredient taxol that can be extracted from its bark, twigs, leaves and other parts (Li et al., 2003; Yuan et al., 2002 a, b, c). However, the species has been under much pressure from overuse in recent years and has suffered significantly as a result. To combat this, T. mairei was listed as one of China's class of key protected wild plants in 1999. Biologists were seeking to increase the $T$. mairei population within a framework of forest resource management and genetic conservation.

Seeds of $T$. mairei with a combination of morphphysiological deep dormancy have underdeveloped and dormant embryos which must grow continuously to some length before seed dormancy could be broken. Natural reproduction was low resulting in them becoming endangered. Six types of morph-physiological dormancy are described by Nikolaeva (1977). For example, a deep and simple morph-physiological dormancy, typified by 
seeds of Fraxinus excelsior L. (Villiers and Wareing, 1964) and Jeffersonia diphylla Pers. (Baskin and Baskin, 1989), required alternating temperature stratification before seeds germinated. A dormancy-breaking methodthat employs a combination of warm and cold stratification has been established for seeds of Taxus species (Chien et al., 1995; Devillez, 1976; Suszka, 1985). It showed that Gibberellic Acid (GA) could play an important role in the regulation of seed dormancy and germination (Hilhorst and Karssen, 1992; Luckwill, 1952).

Similarly, an increase in GA concentrations during cold stratification and a relation to GA sensitivity may induce seed germination in many dormant species (Bewley and Black, 1994; Karssen et al., 1989). However, the delicate relation between dormant and ready to germinate seeds of $T$. mairei species during warm and cold stratification treatments has not been investigated. It is very important to understand the nature of seeds viability and their ultra structure.

Over the past decades, there were many SEM and TEM studies on the ultra structure of plant (Fujikawa and Kuroda, 2000; Zhang and Lu, 1998; Li et al., 2000; Hong et al., 2001; Xiang and Fu, 1998; Yang et al., 2009; Zhang et al., 2009), but only piecemeal research has been carried out on the changes of the ultra structure of $T$. mairei seeds during cold stratification followed by warm stratification. It is unknown how the embryos are enlarged after seed shedding.

In order to carry out an in-depth study in this experiment, SEM and TEM technology was used to observe changes in the micro-morphological structure and characteristics in the stem epicotvle of $T$. mairei seeds, and to investigate the related micro-morphological changes of exogenous GA treatment during the periods of warm and cold stratification necessary to break the dormancy of $T$. mairei seeds. These results are helpful in understanding the actual physiological and biochemical processes during alternating temperature stratification and provide reference information of $T$. mairei seeds stratification for further study.

\section{MATERIALS AND METHODS}

T. mairei fruits aged 20 to 40 years consisting of scarlet or green cuplike arils were collected in Xiushui County, Jiujiang City, Jiangxi Province of the People's Republic of China, in an evergreen and deciduous broad-leaved mixed forest at $400-500 \mathrm{~m}$ above sea level in valleys and on slopes. Arils were collected; seeds were recovered and macerated in water. The seeds were naturally dried and then sealed in polyethylene bags and stored in a refrigerator. Experimental materials were fresh seeds. TGW was $65.05 \mathrm{~g}$.

\section{Determination of the size of embryo}

A small amount of seeds were taken out from A0, A1 and A2 treatments at regular 2 month intervals and dissected to observe, under an electric microscope, changes in embryo morphology development as well as changes in the size of the embryo. Each treatment was carried out with 3 replicates and 10 embryos for each repeat.
Three (A0-A2) treatments were applied to these seeds. The A0 air-dried seeds were immersed in $25^{\circ} \mathrm{C}$ warm water for $48 \mathrm{~h}$. The A1 seeds were immersed in $200 \mathrm{mg} \mathrm{l}-1 \mathrm{GA}_{3}$ for $48 \mathrm{~h}$, and then mixed with the seeds and wet sand ratio of $1: 3$ stratification. They were first stratified by variable temperature in $23 / 10^{\circ} \mathrm{C}(12 \mathrm{~h}$ light) for 4 months, and then placed in $5^{\circ} \mathrm{C}$ cold stratification for 4 months. The A2 air-dried seeds were soaked in water at $25^{\circ} \mathrm{C}$ for $48 \mathrm{~h}$, and mixed with moist sand and placed directly outdoors in natural stratification for 8 months (Chien et al., 1998).

\section{Scanning electron microscopy}

Embryos were taken out after removing the spermoderm of different stratification in A1 treatment of Taxus seeds. These embryos were fixed in $2.5 \%$ glutaraldehyde, washed with $0.1 \mathrm{~mol} / \mathrm{l}$ phosphate buffer and fixed by $1 \%$ osmium tetroxide. They were then washed with $0.1 \mathrm{~m}$ phosphate buffer again, dehydrated with ethanol, converted by using iso-amyl acetate resin, bonded with a drying instrument on the HCP-2 critical point, then finally sprayed gold with an IB-v ion sputtering instrument and filmed with an SEM (PHILIPS SEM-505) (Kuo-Huang, 1990).

\section{Transmission electron microscopy}

Embryos were taken out after removing the spermoderm of different stratification in A1 treatment of $T$. mairei seeds. These embryos were fixed in a mixture of $6 \%$ glutaraldehyde and $0.1 \% \mathrm{~mol} / \mathrm{L}$ phosphate buffer $\mathrm{pH} 7.2$ for $18 \mathrm{~h}$. They were then fixed by $2 \%$ osmium tetroxide in the same buffer for $6 \mathrm{~h}$. Fixed samples were dehydrated by all levels of alcohol, embedded by Epon812 resin and sliced using an LKB-V-type ultra-thin slicing machine. Sections were stained with uranyl acetate and lead citrate and TEM was observed through JEM100CX-2 (Spurr, 1969).

\section{RESULTS AND DISCUSSION}

\section{Embryonic size changes during stratification}

Embryo development was observed during the stratification. The freshly harvested seed embryo had an integrated structure including radicles, hypocotyls and cotyledons, although its size was small as observed under the 10x microscope. The ivory-white embryo could not be easily observed and the embryo and endosperm were hardly stripped. The majority of embryos were in the shape of a wooden club or spindle. Embryos and endosperms were easily peeled for stratification after a period of time, and most of the embryos were elongated in to a lanceolate shape. Some green embryo cotyledons could be clearly observed after four months of warm stratification. The embryo was green and shiny after six months of stratification.

The changes of embryo size in stratification are shown in Table 1. Compared with newly harvest seeds, $A 0$ and A1 have grown seed embryo. The embryo in A1 grew faster than that in $\mathrm{A} 0$. The length and width of the embryo in A1 were 1.6 and 1.4 times that of the newly harvest seeds by the end of stratification. However, the embryo of A2 had very little change, which is similar to reports by Chien et al. (1998). The warm stratification facilitated the flow of embryo nutrients and gradually improved the volume of embryos. 
Table 1. Changes in embryo size of $T$. chinensis var. mairei seed.

\begin{tabular}{|c|c|c|c|c|c|c|c|c|}
\hline \multirow{2}{*}{ Index } & \multirow{2}{*}{ Treatments } & \multicolumn{5}{|c|}{ Stratification/months } & \multirow{2}{*}{$\mathbf{F}$} & \multirow{2}{*}{$\mathbf{P}$} \\
\hline & & 0 & 2 & 4 & 6 & 8 & & \\
\hline \multirow{3}{*}{ Embryo length/mm } & $\mathrm{A} 0$ & $1.95 \pm 0.07^{\mathrm{Aa}}$ & $2.04 \pm 0.18^{\mathrm{Aa}}$ & $2.31 \pm 0.03^{\mathrm{Bb}}$ & $2.46 \pm 0.09^{\mathrm{Bbc}}$ & $2.67 \pm 0.04^{\mathrm{Cc}}$ & 26.337 & $0.000^{* *}$ \\
\hline & $\mathrm{A} 1$ & $1.95 \pm 0.07^{\mathrm{Aa}}$ & $2.07 \pm 0.06^{\mathrm{ABa}}$ & $2.23 \pm 0.04^{\mathrm{Ba}}$ & $2.60 \pm 0.09^{\mathrm{Cb}}$ & $3.03 \pm 0.21^{\mathrm{Dc}}$ & 49.859 & $0.000^{* *}$ \\
\hline & $\mathrm{A} 2$ & $1.95 \pm 0.07^{\mathrm{Aa}}$ & $2.02 \pm 0.12^{\mathrm{Aa}}$ & $2.07 \pm 0.14^{\mathrm{Aa}}$ & $2.10 \pm 0.10^{\mathrm{Aa}}$ & $2.15 \pm 0.06^{\mathrm{Aa}}$ & 1.691 & 0.228 \\
\hline \multirow{3}{*}{ Embryo width/mm } & A0 & $0.52 \pm 0.01^{\mathrm{Aa}}$ & $0.50 \pm 0.04^{\mathrm{Aa}}$ & $0.60 \pm 0.03^{\mathrm{Bb}}$ & $0.62 \pm 0.02^{\mathrm{Bb}}$ & $0.63 \pm 0.01^{\mathrm{Bb}}$ & 19.895 & $0.000^{* *}$ \\
\hline & $\mathrm{A} 1$ & $0.52 \pm 0.01^{\mathrm{Aa}}$ & $0.51 \pm 0.02^{\mathrm{Aa}}$ & $0.63 \pm 0.01^{\mathrm{Bb}}$ & $0.63 \pm 0.04^{\mathrm{Bb}}$ & $0.74 \pm 0.04^{\mathrm{Cc}}$ & 39.776 & $0.000^{* *}$ \\
\hline & $\mathrm{A} 2$ & $0.52 \pm 0.01^{\mathrm{Aa}}$ & $0.53 \pm 0.05^{\mathrm{Aa}}$ & $0.51 \pm 0.04^{\mathrm{Aa}}$ & $0.53 \pm 0.05^{\mathrm{Aa}}$ & $0.55 \pm 0.06^{\mathrm{Aa}}$ & 0.441 & 0.777 \\
\hline
\end{tabular}

Note: upper case letters show multiple comparisons on $\alpha=0.05$, lower case letters on $\alpha=0.01$. The difference between the same letters was not significant on the same row, though distinction existed between different letters. ${ }^{* *} \mathrm{P}<0.01$.

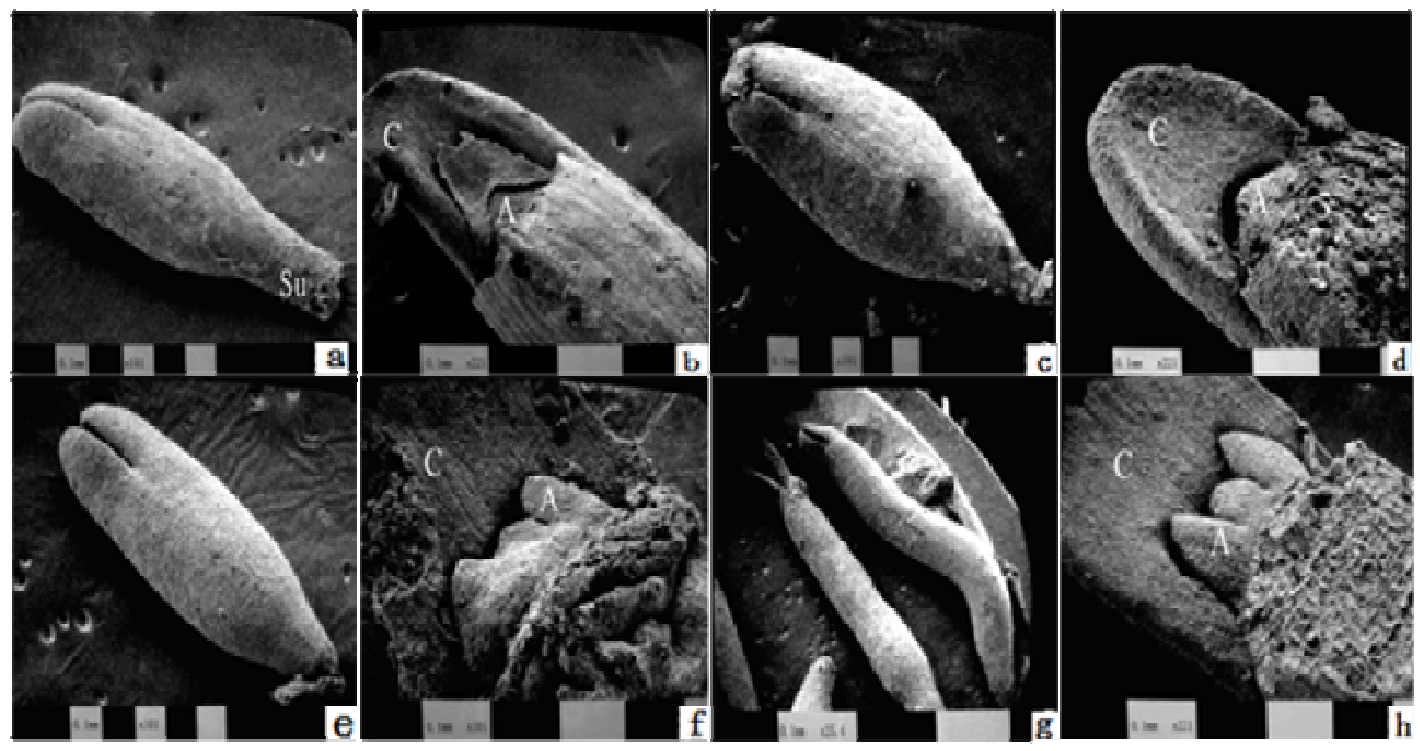

Figure 1. (a-h) SEM micrographs of embryos and shoot apical meristems of T. chinensis var. mairei. C-cotyledon; A-stem of the apical meristem; Su-suspensor.

\section{Changes in embryo structure during stratification}

\section{Structure of untreated embryo}

The length of the mature and plump $T$. mairei seeds was 3.8-5.8 $\mathrm{mm}$. Each seed contained a small embryo that was composed of axis, cotyledon, hypocotyl and radicle. There was a small apical meristem (growing point) in the inter-cotyledon (Figure 1a, b). During the same period, the most obvious characteristic observed under TEM was a large number of lipids in the embryonic cells of the outer layer of embryonic cells, and it was also observed that the fat filled the entire cell (Figure 2a, b).

The cell wall structure was integrated and the cells were closely linked and packed. The nuclear membrane was distorted and retracted, containing many smaller high-electron-dense materials. The embryo of the middle cell lipids had disappeared and formed a large number of vacuoles and different shapes of high-electron-dense materials (Figure $2 \mathrm{c}, \mathrm{d}$ ). There was no deformation in the outer cell wall of the embryo cells, but there was deformation of the inner individual cell wall. Figure 1 show the morphology and vertical profiles of Taxus embryo in different stratification periods. Figures $1 \mathrm{a}, \mathrm{b}$ are the control (untreated), Figure 1c, $d$ show the embryo morphology and profiles in the day $23^{\circ} \mathrm{C} /$ night $10^{\circ} \mathrm{C}$ warm stratification for 4 months. Figure 1e, f show the warmtemperate stratification at 4 months, plus $5^{\circ} \mathrm{C}$ cold stratification situation for 2 months. Figure $1 \mathrm{~g}$, h show the embryo as a whole (that is, when germinating) for warm stratification at 4 months and cold stratification at 4 months. 

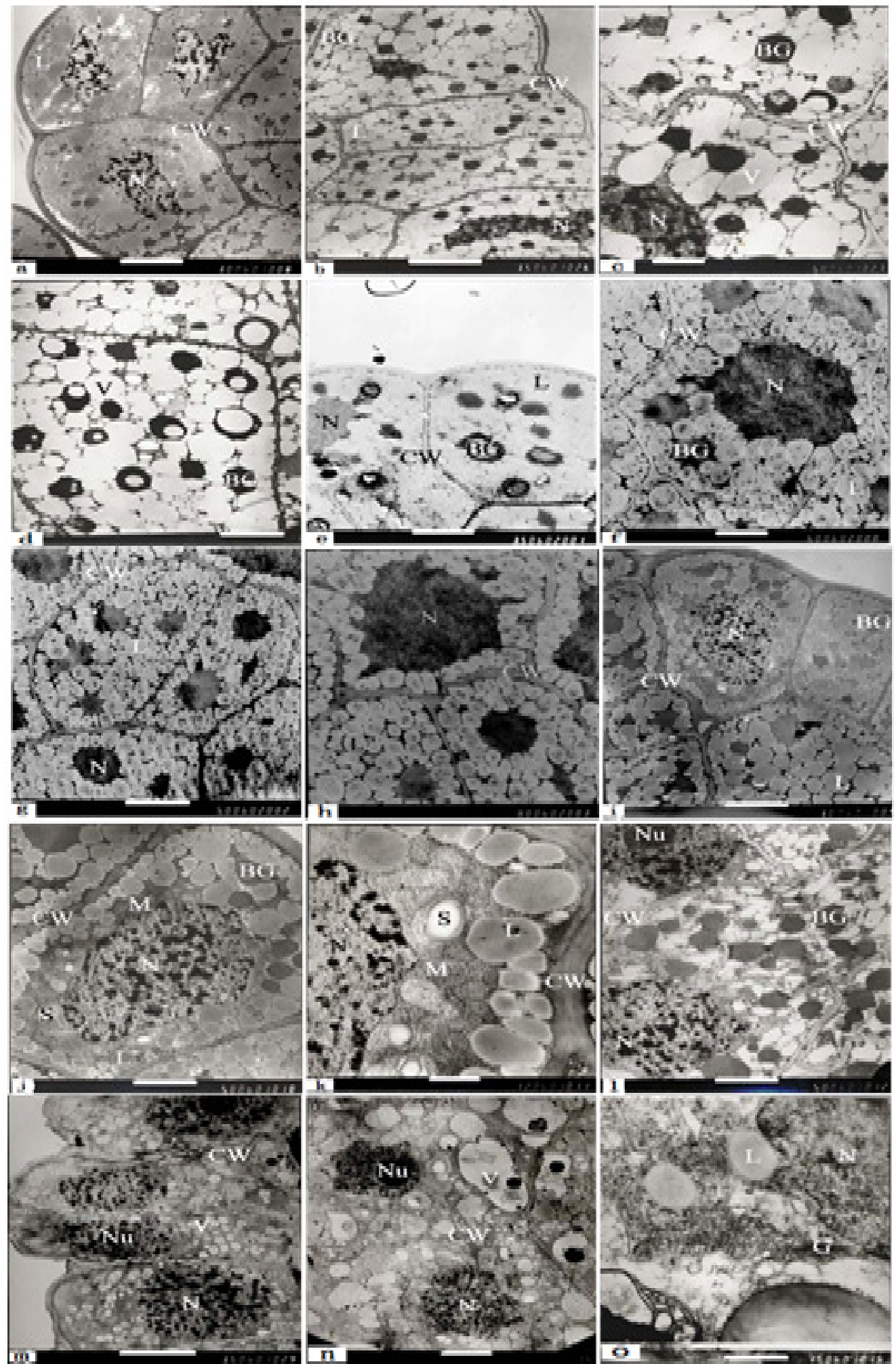

Figure 2. a-o TEM micrographs of the embryo of $T$. chinensis var. mairei, BG-high electron density of particulate matter; CW-cell wall; G-Golgi comple, x; L-liposome; M-mitochondria; N-nucleus; Nu-nucleolus; V-vacuole; S-starch grains. Scale: $a=5 \mu \mathrm{m}, b=5 \mu \mathrm{m}, c=2 \mu \mathrm{m}, \mathrm{d}=5 \mu \mathrm{m}, \mathrm{e}=2 \mu \mathrm{m}, \mathrm{f}=3 \mu \mathrm{m}, \mathrm{g}=2 \mu \mathrm{m}, \mathrm{h}$ $=4 \mu \mathrm{m}, \mathrm{i}=5 \mu \mathrm{m}, \mathrm{j}=3 \mu \mathrm{m}, \mathrm{k}=1 \mu \mathrm{m}, \mathrm{I}=3 \mu \mathrm{m}, \mathrm{m}=5 \mu \mathrm{m}, \mathrm{n}=6 \mu \mathrm{m}, \mathrm{o}=1 \mu \mathrm{m}$. a-o for different period of stratification $T$. mairei embryo ultrastructure variety. a-d for the control (untreated), e-h in the day- $23^{\circ} \mathrm{C} /$ night $10^{\circ} \mathrm{C}$ warm stratification for 4 months after the ultrastructure of embryonic cells, i-I for the Warm stratification for 4 months, plus $5^{\circ} \mathrm{C}$ cold stratification for two months later, m-o warm stratification for 4 months and cold for 4 months later ultrastructure of embryonic cells. 


\section{Structure of embryo after warm stratification}

Embryo length and width increased considerably after being stratified at $23 / 10^{\circ} \mathrm{C}$ ( $12 \mathrm{~h}$ light) for 4 months. The width of the embryo in A1 was 1.38 times that of the fresh embryo. The cotyledons and stem apical meristems in A1 increased (Figure 1c, d). During this period, there were still many lipids in the embryonic cells (Figure 2e-h), and most of the nuclei were spherical or oval. The cell structures of the middle and outer layer was basically uniform and the cell walls were not distorted.

\section{Embryo structure after warm and cold stratification}

Compared with warm stratification, the size of the embryos, cotyledons and apical meristems increased after cold stratification for more than 2 months and continued to show slight cotyledon rupturing (Figure 1e, f). An intact structure and larger nuclei in the embryo cells were observed by TEM. The exoplasm of embryonic cells contained many organelles, such as normal nuclei, a small number of starch granules and mitochondria, and a wealth of high-density electronic material (Figure 2i, j). The lipid material in the cell outer section was reduced significantly more than it was after warm stratification. Nucleoli were clearly visible in the middle of the embryo cells (Figure 2k, l) and the nucleus was intact. A few vacuoles and similar quasi-circular or oval high electrondense material and tortile cell walls were observed. These characteristics sufficiently demonstrated that the cell ultrastructure at that phase had already started the process of germination. The number of mitochondria increased and the storage substances (lipids) of the cells began to degrade in the germination process.

\section{Structure of embryo at germination}

The embryos, cotyledons and stem meristem stems were enlarged after warm stratification for 4 months following cold stratification for 4 months (Figure 1g, h). Additionally, the outermost layer of embryonic cells can be observed from the TEM figure of embryo germination (Figure $2 \mathrm{~m}$ ), in which can be seen the following: one or two nucleoli in each cell nucleus, normal cell structure, lipids disappearance, many smaller vacuoles that containing a small amount of high-electron-dense materials, nucleus enlarge and normal, with a mild distortion of cell wall. The embryo structure in the middle was approximately the same as that on the outer side. The number of vacuoles increased slightly (Figure 2n) and more phagocytic substances were formed, and there was also an increase in high electron-dense material. The cell wall of the middle embryo was not significantly distorted and the cytoplasm contained a small amount of lipid material. Golgiosome and other organelles were observed (Figure 20). These observations are consistent with research findings reported elsewhere (Chien et al., 1998). These observations also showed that at that time the embryo storage had degraded to a very low level and that the embryo had begun to germinate.

\section{Conclusion}

While some plant embryos often developed incompletely when their seeds were maturely formed, the $T$. mairei embryo already had radicles, hypocotyls, plumules and cotyledons when its seeds were ripe. However, the embryo was small and not yet filled with an embryo cavity, so the seeds could not germinate and needed after-ripening. The embryo cell split and increased to complete embryonic development during the warm stratification process, but there were no significant changes to the size of the embryo compared with natural stratification.

The growth rate in length and width of the embryo were 1.6 times and 1.4 times greater than those of original embryo, respectively. The number of cotyledons and stem apical meristems had also increased during the 4 months of warm stratification. Compared with the control, there was no significant change in the ultrastructure and it still contained a large number of lipid materials. After 2 months of cold stratification, significant changes in the ultrastructure occurred but not in the embryo, cotyledon and stem apical meristem group. At this point, the nucleus volume was large, nucleolus and a small number of starch grains appeared, lipids significantly reduced, and the number of mitochondria increased.

These results showed that cold stratification was important for the storage material fat of $T$. mairei seed to degrade. By the time of germination, the cotyledons spread and the stem meristem cells had clearly differentiated into two leaves primordium. At this stage, the most obvious change in the ultrastructure was that the lipids had almost completely degraded leading to energy provision for the seed germination. Therefore, we investigated the changes of ultrastructure in the stem apical meristem of $T$. mairei seed embryo using SEM and TEM during the periods of warm and cold stratification necessary to break the dormancy of $T$. mairei seeds. These results suggest that the strong seed dormancy of $T$. mairei could be caused by the underdevelopment of embryos in freshly shed seeds.

We concluded that warm stratification with alternating temperature caused embryo cells to split and increase in number, which led to their release from physiological dormancy and subsequently germination of the $T$. mairei seeds.

\section{ACKNOWLEDGEMENT}

The work reported here has been funded by Projects from Jiangxi Province Natural Science Foundation of China (20114BAB214007, 20122BAB214025). 


\section{REFERENCES}

Baskin JM, Baskin CC (1989). Seed germination ecophysiology of Jeffersonia diphylla, a perennial herb of mesic deciduous forests. Am. J. Bot. 76:1073-1080.

Bewley JD, Black M (1994). Seeds: physiology of development and germination. Second Edition. New York and London: Plenum Press, New York. London.

Chien CT, Long L, Huang K, Lin TP (1998). Changes in ultrastructure and abscisic acid level, and response to applied gibberellins in Taxus mairei seeds treated with warm and cold stratification. Ann. Bot. 81:41-47.

Chien CT, Yang JJ, Chung YL, Lin TP (1995). Germination promotion of Taxus mairei seed by combination of warm and cold stratification. Bull. Taiwan For. Res. Inst. 10:331-336.

Devillez F (1976). Afterripening and dormancy breakdown in Taxus baccata $L$. seeds. In: IUFRO Proceedings of the 2nd International Symposium `Physiology of Seed Germination'. Fuji, Japan. pp. 47-61.

Fujikawa S, Kuroda K (2000). Cryo-scanning electron microscopic study on freezing behavior of xylem ray parenchyma cells in hardwood species. Micron. 31:669-686.

Hilhorst HWM, Karssen CM (1992). Seed dormancy and germination: the role of abscisic acid and gibberellins and the importance of hormone mutants. Plan. Growth Regul. 11:225-238.

Hong L, Elbl T, Ward J, Franzini-Armstrong C, Rybicka KK, Gatewood BK, Baillie DL, Bucher EA 2001. MUP-4 is a novel transmembrane protein with functions in epithelial cell adhesion in Caenorhabditis elegans. J. Cell Biol. 154:403-414.

Karssen CM, Zagorski S, Kepczynski J, Groot SPC (1989). Key role for endogenous gibberellins in the control of seed germination. Ann. Bot. 63:71-80.

Kuo-Huang LL (1990). Calcium oxalate crystals in the leaves of Nelumbo nucifera and Nymphaea tetragona. Taiwania 35:178-190.

Li C, Yuan YJ, Wu JC, Hu ZD (2003). A structured kinetic model for suspension of Taxus chinensis var. mairei induced by an oligosaccharide from Frusarium oxysporum. Biotechnol. Lett. 25:I3351343.

Luckwill LC (1952). Growth-inhibiting and growth-promoting substances in relation to the dormancy and after-ripening of apple seeds. J. Hortic. Sci. 27:53-67.

Nikolaeva MG (1977). Factors controlling the seed dormancy pattern. In: Khan AA, ed. The physiology and biochemistry of seed dormancy and germination. Amsterdam. North-Holland. pp. 51-74.
Spurr AR (1969). A low-viscosity epoxy resin embedding medium for electron microscopy. J. Ultrastruct. Res. 26:31-43.

Suszka B (1985). Conditions for after-ripening and germination of seeds and for seedling emergence of English yew (Taxus baccata L.). Arboretum Kornickie. 30:285-336.

Villiers TA, Wareing PF (1964). Dormancy in fruits of Fraxinus excelsior L. J. Exp. Bot. 15:359-367.

Xiang QP, Fu LG (1998). SEM observation on the structure of leaf inner surface of abies (Pinaceae) and its significance in systematics. Acta. Phytotaxonom. Sin. 36:441-448.

Yang ZH, Wu YX, Lin SQ (2009). SEM observation on the pollen morphology of six Eriobotrya plants. J. Fruit Sci. 26:572-576.

Yuan YJ, Li C, Hu ZD, Wu JC (2002a). A double oxidative burst for taxol production in suspension cultures of Taxus chinensis var. mairei induced by oligosaccharide from Fusarium oxysprum. Enzyme Microb. Tech. 30:774-778.

Yuan YJ, Li C, Hu ZD, Wu JC, Zeng AP (2002b). Fungal elicitor-induced cell apoptosis in suspension cultures of Taxus chinensis var. mairei for Taxol production. Process Biochem. 38:193-198.

Yuan YJ, Li C, Wu JC, Hu ZD (2002c). A model for signal transduction in suspension cultures of Taxus chinensis var. mairei induced by an oligosaccharide from Fusarium oxysporum. Biotech. Lett. 24:407412.

Zhang SS, Zhou YF, Lin XH, Qin SP, Zhang Y, Zhang ZW, Wang QT (2009). Scanning electron microscope observation of three species on pollen grain morphology and leaf Epiderm shape in Gramineae Triticeae. Agric. Sci. Tech. 10:86-89.

Zhang ZY, Lu BR (1998). The structural features of leaf epidermis in Oryza and their systematic significance. Acta. Phytotaxonom. Sin. 36:8-18. 